\title{
CLARÍN Y EL DEBATE SOBRE EL NATURALISMO EN ESPAÑA
}

El prólogo de Clarin a la traducción de Trabajo de 1901', que con razón se puede considerar su testamento literario, aśí como otros escritos suyos anteriores sobre Zola y la escritura experimental, deben situarse en el contexto ideológico-cultural de los debates que acerca del idealismo, el realismo y el naturalismo tuvieron lugar en la España de la segunda mitad del siglo XIX. O lo que viene a ser lo mismo, en torno a las discusiones y polémicas que proliferaron en aquellos años en torno al entonces candente tema del positivismo.

La sociedad española decimonónica, con una revolución burguesa prácticamente por hacer, no se hallaba en condiciones de habérselas con un proceso de positivación, del que Francia, país temido por unos y admirado por otros, era el mayor exponente. España temía que la influencia del positivismo francés fuera a

1 Cf. Émile Zola, Trabajo, ed. F. Caudet según la traducción de L. Alas, "Clarín", Ediciones de la Torre, Madrid, 1991. La edición de Clarín fue publicada en Barcelona por la Casa Editorial Maucci. A lo largo de este trabajo utilizaré las siguientes abreviaturas:

Hibbs-Lissorgues = S. Hibbs-Lissorgues, "La iglesia católica y el naturalismo", en Realismo y naturalismo en España en la segunda mitad del siglo xix, ed.

S. Hibbs-Lissorgues, Anthropos, Barcelona, 1988.

Lissorgues = YVAN Lissorgues, Clarín politico, t. 1, Institut d'Études Hispaniques et Hispano-américaines, Toulouse, 1980.

NúÑ̃EZ = D. NúNẼ, La mentalidad positiva en España: desarrollo y crisis, Tucar Ediciones, Madrid, 1975.

Ramos-Gascón = Antonlo Ramos-Gascón, "Clarin". Obra olvidada, Júcar, Madrid, 1973.

Tintoré $=\mathrm{M}^{\mathrm{a}} \mathrm{J}$. Tintoré, "La Regenta" de Clarín y la critica de su tiempo, Lumen, Barcelona, 1987.

Torres $=$ D. Torres, Los prólogos de Clarín, Playor, Madrid, 1984 .

Trabajo = É. ZoLA, Trabajo, ed. cit. 
poner en tela de juicio sus "esencias espirituales", un acervo patrio que muchos se habían impuesto salvaguardar a toda costa. Para ello habían autoproclamado a España la representante de unas modélicas formas tradicionales de vida, que chocaban frontalmente con la modernidad que implicaba el nuevo culto al materialismo científico.

Diego Núñez ha observado que, a pesar de las muchas resistencias, se produjo en algunos sectores sociales un débil acercamiento a las tesis positivistas, que sin duda tuvieron "saludables efectos en una situación cultural como la española, sobrecargada de recursos esteticistas y moralistas, cuando no puramente teóricos, con sus naturales secuelas mistificadoras, imponiendo un enfoque más riguroso y esclarecedor en el tratamiento de los prem blemas nacionales" (Núnez, pp. 15-16). Pero, con todo, falla" ron los dos pilares en los que se asentó el positivismo en Francia: el orden social que emergió de la Revolución francesa y el desarrollo de las ciencias de la naturaleza, que tuvieron una enorme proyección tecnológica. Pues bien, en España no se dieron estos factores. Y Diego Núñez se detiene a analizar lo que ello supuso para España:

En cuanto al primero, nos encontramos aquí con la ausencia de una auténtica transformación burguesa de las estructuras nacionales y la consiguiente existencia de una realidad social completamente desajustada y desdoblada entre los poderosos vestigios del Viejo Régimen y los conatos de implantación institucional del Nuevo; dualismo quo sc patentizará, por cjemplo, en el nivel político y cultural, en las sucesivas guerras civiles carlistas o en la escisión de la consciencia nacional con motivo de diversas polémicas, tales como la de "la ciencia española" o el tema de "las dos Españas", y desde la perspectiva socio-económica, en la carencia de un efectivo mercado nacional, en la estructura social semifeudal o en los numerosos contrastes entre el medio rural y el urbano, la España interior y la periférica, etc. (ibid., p. 17).

Así las cosas, concluye Diego Núñez que estas insuficiencias, como no podía ser de otra manera,

harán que el estadio positivo - siguiendo la terminología comtiana- no disfrute en España de la misma salud que en el vecino país francés. Mientras en Francia el propio Gambetta se declaraba públicamente, al subir al poder, "servidor libre y desinteresado del Positivismo", en el Ateneo madrileño se discutía acaloradamente 
si "el actual movimiento de las ciencias naturales y filosóficas en sentido positivista constituye un grave peligro para los grandes principios morales, sociales y religiosos en que descansa la civilización". Esto es, si en Francia la doctrina positiva había llegado a convertirse en la más firme fundamentación de la "política que ha salvado la República”, en España, por el contrario, la burguesía no había conseguido llevar a cabo las debidas transformaciones en la realidad del país que permitieran identificar la filosofía positiva con los intereses nacionales (id., p. 18).

Hay testimonios un tanto escalofriantes de lo que este desfase supuso para la ciencia española. En 1854, José de Revilla, uno de los principales autores del Plan de Instrucción Pública, decía que para luchar contra el pobre panorama de la ciencia experimental en España, era menester:

crear intereses generales, que liguen, que estrechen a los ciudadanos entre sí; no intereses metafísicos, que por sí propios se desvanecen, sino intereses reales y positivos, en que funden su bienestar, a que por necesidad estén adheridos, y que lleguen a formar sus costumbres y hábitos de moralidad... Cuando en España se lleguen a crear intereses nacionales, esto es, cuando tengamos extenso comercio marítimo, bonancible y creciente la industria y el tráfico, más extensa y próspera la agricultura... entonces tendremos ideas propias y fijas; entonces no tocaremos en sistemas absurdos; entonces no iremos a buscar éstos y aquéilas en ios libros franceses (id., p. 206).

Desde un punto de vista político, recuerda también Diego Núñez que Manuel de la Revilla, unos años más tarde,

no cesa de insistir en los debates del Ateneo, durante el curso 1875 . 1876, que el positivismo es a la vez "liberal y conservador": "liberal, porque reconoce la imperfección de muchas instituciones jurídicas y aspira a reformarlas y ponerlas en armonía con las necesidades de la naturaleza humana y de la justicia; conservador, porque sabe nuy bien... que las reformas han de ser suaves transformaciones y no revoluciones violentas". De este modo, la mentalidad positiva contribuirá de manera decisiva, en el último cuarto del siglo XIX, a perfilar teóricamente los nuevos rumbos reformistas del liberalismo español (id., p. 15).

En el plano literario, que como decía más arriba hay que situar en un contexto más amplio, se produjo un muy duro deba- 
te entre quienes defendían el idealismo frente al realismo y entre quienes, desde las filas del idealismo o de un realismo autóctonotradicional, se oponían frontalmente al experimentalismo de la escuela naturalista francesa. Como telón de fondo, había un reaccionismo visceral y/o un sentimiento nacionalista, que llegó a prender - me detengo en ello más adelante - incluso en hombres de probado liberalismo.

La polémica entre el idealismo y el realismo tuvo lugar, principalmente, en las décadas de 1860 y 1870 . Emilio Nieto, en el ensayo "El realismo en el arte contemporáneo", publicado en 1875, se congratulaba, por una parte, de que "nuestra patria es quizás el país que por mayor espacio de tiempo ha sabido resistir la invasión, encastillada detrás de los fuertes muros de su tradicional idealismo", pero lamentaba, por otra parte, que finalmente "se ha visto forzada a dejar paso franco a la nueva tendencia" $y$, así, en aquellos momentos era

el realismo moneda corriente entre nosotros, aunque por fortuna no tanto todavía como en Francia, donde impera en absoluto, acrecentando sin medida sus extravíos y dando patente ejemplo del extremo a que es capaz de llevar ese pueblo, tornadizo y ligero por naturaleza, envuelto en el torbellino de la moda y arrastrado por su ansia inagotable de novedades, una dirección, que estudiada en su origen, reducida a racionales términos, pudo haber sido tan legítima como saludable ${ }^{2}$.

Manuel de la Revilla, en "Del estado actual del teatro español" , también aparecido en 1875, se oponía con virulencia a la influencia francesa en el teatro español, para terminar diciendo que en España existía, en cambio, un "realismo legítimo y razonable", con excelentes representantes: Bretón de los Herreros, Ventura de la Vega, Ayala y Tamayo...

Rechazamos como anti-artísticas las reproducciones exactas y detalladas de las hediondeces y miserias más bajas de la sociedad, erigidas en único objetivo del arte dramático: no queremos sustituir la pasión con la enfermedad, el afecto con la sensación, el cuadro dramático con el fenómeno morboso, ni excluir del teatro el culto del bien, de la moralidad y del pudor. Si el realismo es eso; si han de personificarlo rameras sentimentales como Margarita Gau-

${ }^{2}$ E. NiETo, “El realismo en el arte contemporáneo", Revista Europea, enero-febrero 1875. 
tier, almas de cieno como Monjoye, y casos teratológicos como Fernanda y Frou-Frou y los personajes de la Femme de Claude; si la moral de este nuevo arte dramático se ha de compendiar en Les Idées de Madame Aubary, Le Supplice d'une femme, La Dame aux Camélias y otras producciones de este género; si las costumbres que se ofrezcan a los ojos del público han de ser las que se pintan en La Famille Benoiton, Les Filles de marbre y Le Demi-Monde, protestamos contra este teatro a nombre del arte profano, de la moral menospreciada y de la humanidad ultrajada y calumniada de un modo verdaderamente incalificable. Pero este teatro no ha formado escuela en España. Sus obras principales desfiguradas al trasladarse a la escena española, han caído bajo el peso de la indignación pública, y el único escritor que ha intentado aclimatar ese género entre nosotros, ha resultado vencido en el combate, a pesar de su indiscutible ingenio y de la tendencia relativamente moral de sus composiciones ${ }^{3}$.

Juan Valera, en el artículo 'El teatro español', publicado en 1876 en la Revista Europea, daba estas peregrinas razones a la hora de explicar su opinión desfavorable a la protección oficial del teatro en España:

Se dice que los actores son malos; pero ¿los haría buenos la protección oficial? Aquí se puede repetir la misma comparación de la cosecha. Unas veces se dan más actores buenos que otras. Se dice que en España no tenemos tantas y tan buenas actrices como en Francia; es verdad, pero para esto hay razones determinadas que, no por pertenecer a cierto género, son menos exactas. Aquí una actriz es una señorita como otra cualquiera, que vive con su familia, y cuya vida en nada se diferencia de la de las demás jóvenes de la clase media, como sea en que, en vez de dedicarse a los cuidados domésticos y labores de su sexo, tiene que aprender sus papeles, asistir a los ensayos y salir por la noche a las tablas, generalmente bajo la vista y vigilancia de su madre o de su marido. En Francia no sucede esto por regla general; allí una actriz vive independiente y libre; tiene trato íntimo y diario con toda clase de artistas; generalmente sostiene una temporada relaciones íntimas con un banquero, otra con un lord, otra con un nabah de la India, y a veces con monarcas extranjeros; gasta, derrocha, asiste a todas partes, todo lo ve y todo lo sabe; y, naturalmente, de este cúmulo de relaciones y de roces, nacen conocimiento, enseñanzas e ilustraciones que se traducen en dominio de la escena, desembarazo, flexibilidad para varios géneros, tipos y papeles, y esos mil detalles

${ }^{3}$ M. DE la Revilla, "Del estado actual del teatro español”, La Ilustración Española y Americana, 2 de diciembre 1875. 
que tanto nos encantan en la actriz francesa. ¿Cómo hemos de exigir esto a nuestras dignas actrices? Aquí no vienen kedives ni potentados, aquí no hay el demi-monde francés, aquí, afortunadamente, estamos muy por debajo de ese brillante oropel ${ }^{4}$.

Igualmente crítico con el realismo fue Juan Mañé y Flaquer, quien, en 1884, en el prólogo a la novela Nora de la Baronesa von Brackel, decía:

El realismo se dirige a nuestros sentidos y aspira al dominio de nuestras pasiones; es la materia que obra sobre el hombre fisiológico; no la inteligencia que mueve el hombre psicológico. Para el realismo, el deber del hombre se limita a la satisfacción de sus pasiones en esta vida, que considera única: para el espiritualismo. el deber del hombre es su purificación, es decir, el sacrificio de sus pasiones a una aspiración que no se satisface sino en una vida mejor que la presente. El fin estético del realismo, como el fin moral del materialismo, es apartar al hombre de Dios para acercarle al bruto; el fin del arte espiritualista, es elevar y purificar el espíritu del hombre para acercarle a Dios, tipo y modelo de toda perfección ${ }^{5}$.

Sin embargo, algunas voces destacadas como la de Vidart salieron en defensa del realismo o, lo que venía a ser lo mismo, de Francia. En una recensión del debate en torno al teatro español celebrado en la Sección de Literatura y Bellas Artes del Ateneo de Madrid, se atribuía a Vidart la opinión, frente a las de Revilla y Valera, de que la decadencia del teatro español se debía a la resistencia a seguir la senda del realismo:

Declárase partidario del realismo, tal como lo proclama y practica la escuela francesa representada por Dumas, hijo, y Victoriano Sardou; y dice que a nuestros escritores les falta el valor suficiente para cultivar resueltamente esta escuela, que es la única que puede salvar nuestro teatro, por lo mismo que es la única verdadera. Cree también el Sr. Vidart que falta también a nuestros poetas la originalidad que en su concepto reúne la moderna escuela realista francesa ${ }^{6}$.

${ }^{4}$ J. Valera, "El teatro español", Revista Europea, 16 de abril 1876.

5 Biblioteca "Arte y Letras", Barcelona, 1884, p. xiii.

6 “'Se halla en decadencia el teatro español?", Revista de Europa, 9 de abril 1876 . 
Pero las opiniones contrarias al realismo eran, sin la menor duda, mucho más numerosas. A las ya mencionadas iremos añadiendo otras. Así, las de Alarcón y Nocedal, ardientes defensores del idealismo y de la moral en el arte ${ }^{7}$. Los ataques de Alarcón a Fanny, la novela de Ernest Feydeau, son bastante elocuentes de su acendrado antirrealismo, o lo que venía a ser lo mismo: de su fobia a la cultura francesa y a Francia en general. Partiendo de unos juiciosos comentarios de Eugenio Montegu aparecidos en la Revue des Deux Mondes, aventuraba Alarcón estas apostillas:

Fanny es una novela íntima del género realista -así la ha llamado Eugenio Montegu... Pero lo que no se le ha ocurrido decir a este critico eminente, es que la frase nowela intima del género reabita envuelve ya una censura. Sernejantes novelas no son novelas; son historias particulares que antiguamente se contaban al confesor; que después fue moda referir sotto voce a los amigos, y que hoy se pregonan desvergonzadamente en los sitios públicos; lo cual es completa idea de las costumbres parisienses ${ }^{8}$.

Para Alarcón esas costumbres reflejaban de manera inequívoca el estado de decadencia moral de la sociedad francesa, un cadáver que se hallaba "en plena putrefacción" y cuya "fetidez va llegando a nuestras narices". . Por consiguiente, Francia era una influencia tan nefasta como inevitable. Pero, en cualquier caso, había que defenderse de ella. Una de las maneras más expeditivas para lograrlo consistía, según el autor de El escándalo, en defender "la moral en el arte". Asítituló precisanente el discurso de su ingreso en la Real Academia de febrero de 1877, en donde, entre otras lindezas - con el tiempo todavía fue radicalizando más sus posturas--, llegó a decir:

En el siglo presente, la literatura francesa ha ido descendiendo, y haciendo descender las letras latinas, desde el romanticismo objetivo, que predicó lo inmoral, creyéndolo moral, hasta los géneros bufo y sucio que enseñan lo inmoral, a sabiendas de que lo es... Pero respetemos al delincuente en la hora providencial del castigo... Respetemos el dolor de un pueblo humillado, y pidamos tan sólo que

${ }^{7}$ Cf. G. DAviEs, “The Spanish debate over Idealism and Realism before the impact of Zola's Naturalism", PMLA, 84 (1969).

${ }^{8}$ P. A. DE Alarcón, "Fanny, novela de M. Ernest Feydeau”, en Juicios literarios y artísticos, Imprenta de A. Pérez Dubrull, Madrid, 1883, p. 106. Escribió este artículo en 1858.

${ }^{9}$ Loc. cit. 
la pena que le ha impuesto la severidad alemana vaya seguida de escarmiento $^{10}$.

Alarcón había convertido así a Bismarck en una especie de providencial ángel exterminador, en el verdugo que había infringido a la Francia decadente un merecido correctivo histórico. El moralismo de Alarcón no podía llegar más lejos. Claro que a fin de cuentas era Francia, según él, la culpable de que se hubiera roto, a lo largo del siglo xix, el beatífico aislamiento español. Pues como había escrito en El sombrero de tres picos - la sorna no impide traslucir la añoranza de un para él pasado idílico:

DDichosisimo tiempo aquel en que nuestra tierra seguia en quieta y pacífica posesion de todas las telaranas, de todo el polvo, de toda la polilla, de todos los respetos, de todas las creencias, de todas las tradiciones, de todos los usos y de todos los abusos santificados por los siglos! ¡Dichosísimo tiempo aquel en que había en la sociedad humana variedad de clases, de afectos y de costumbres! ¡Dichosísimo tiempo, digo... para los poetas especialmente, que encontraban un entremés, un sainete, una comedia, un drama, un auto sacramental o una epopeya detrás de cada esquina, en vez de esta prosaica uniformidad y desabrido realismo que nos legó al cabo la Revolución Francesa! ¡Dichosísimo tiempo, sí!... ${ }^{11}$.

Nocedal, en su respuesta al discurso de ingreso a la Real Academia de Alarcón, coincidió con él -la sintonía entre esos dos abanderados del aislamiento y la moralidad patria era total- en la justificación de la derrota de Francia en Sédan, pues

${ }^{10}$ P. A. DE Alarcón, "Discurso sobre la moral en el arte", en Juicios literarios y artísticos, pp. 55 y 56 . Alarcón en su discurso de ingreso a la Real Academia había llegado a anunciar su deseo de quemar su obra primeriza por no estar plenamente en sintonía con su nueva concepción del arte. Eladio Lezama, con evidente sorna, le respondió en El Solfeo: "Pero Sr. Alarcón de mi alma, si V. para hacerse ultramontano necesita quemar sus obras, ¿con qué título ha pretendido entrar en la Academia? ¿No le basta para ser colega de Nocedal el acto de contrición que ha hecho V. en su discurso...? Yo que $\mathrm{V}$. me contentaría con hacerme ultamontano sin dar a la conversión efectos retroactivos... No tanto celo, Sr. Alarcón. El discurso académico de V... basta y sobra para asegurarle un puesto de honor entre los neos más exaltados y para conquistar las simpatías clericales, y por añadiduría su salvación eterna" (apud G. DAviEs, art. cit., p. 1656).

${ }^{11}$ P. A. De Alarcón, El sombrero de tres picos, Cátedra, Madrid, 1982, pp. 59-60. 
las sociedades que caen en el sensualismo, están a la puerta de la barbarie, y a disposición del primer conquistador que se digne castigarlas. Un pueblo que se pase treinta o cuarenta años danzando el can-can, no solamente en sus bailes de gente perdida, sino en sus dramas, en sus novelas, en sus canciones, en sus cuadros, y hasta en sus edificios, y creyéndose civilizador se entrega a pasear por el mundo su literatura realista, materialista y sensualista, no hay duda, caerá vencido y humillado ante el primer enemigo que con cualquier pretexto le invada. Ese desventurado pueblo se hallará sin fuerzas para defenderse noble, varonil y heroico; verá caer los muros de sus fortalezas al simple rumor de las trompetas de sus invasores, aunque no sean éstos, ni con mucho, el pueblo de Dios; verá sus meretrices bailar el can-can al compás de las músicas extranjeras, a sus avaros contratistas suministrar viveres y provisiones al extranjero enemigo, y buscará su salvación por el momento en las arcas repletas de sus hijos degenerados ${ }^{12}$.

$\mathrm{Y}$ continuaba en estos términos su vehemente y ditirámbica arenga de la que nada tiene perdida:

¡Dichoso mil veces ese pueblo, si contrito vuelve sus ojos hacia Dios, y le desagravia confiando en su Providencia! ¡Infeliz de él, si insensato busca de nuevo placeres en la contemplación de la materia deificada, y se venga de su invasor enseñándole las muecas del can-can! Si esto hace así, que se prepare a ver abrasados sus edificios soberbios, derruidos sus monumentos insignes... Si la sociedad, con la enseñanza de sus filósofos, con los acordes acentos de sus poetas, con la maravillosa y electrizadora palabra de sus oradores, y con la deleitable seducción de las artes, formando un himno magnífico y universal, levanta su corazón hacia arriba, sobre ella como benéfica lluvia derrama Dios sus misericordias. Si persiste en el camino de la perversión, y todo espíritu se materializa, y todo corazón se mancilla, la hora se acerca, el castigo está próximo; los festines se suceden, la literatura realista se multiplica, las artes paganas se embrutecen, el cielo se encapota, la tierra se anega, y desquiciado el mundo, vuelve al estado salvaje.

Éstos son los frutos del materialismo en filosofía, del sensualismo en las costumbres, y del realismo en las letras y las artes ${ }^{13}$.

Terminaba, por tanto, concluyendo, como Alarcón, que lo

${ }^{12}$ C. Nocedal, "Contestación (al discurso de D. Pedro de Alarcón)", en Discursos leidos ante la Real Academia Española, Imprenta Fortanet, Madrid, 1877, pp. 54-55.

${ }_{13}$ Ibid., p. 55. 
nefasto de la cultura francesa era su materialismo, su sensualis. mo y - como compendio de todo ello- su arte realista. La prédica moralista dirigida contra el "sensualismo", quedaba emparedada entre dos premisas ideológicas: el "materialismo" y "el realismo", que era donde el reaccionarismo español verdaderamente identificaba al enemigo.

También Alejandro Pidal y Mon, en "De la metafísica contra el naturalismo", discurso leído en la Real Academia de Ciencias Morales y Políticas, el 3 de abril de 1887, argumentaba, muy en la linea de Nocedal:

Al materialismo cientifico corresponde el naturalismo literario, el

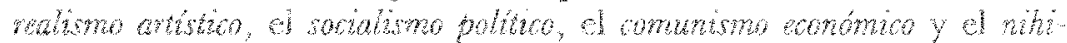
bsmo social... La toología, la metafisica, la jurisprudencia, la medicina, la historia, las ciencias morales y políticas, en fin, hasta las mismas matemáticas, ya lo sabés, han sufrido el golpo de esta invasión del materialismo en la ciencia, viendo destruido su objeto, o rebajada su dignidad, o puesto en duda el carácter evidente de sus axiomas. Todo está ya reducido a encontrar en el campo del microscopio o en los residuos de la teoría, los anillos invisibles aún, de la eterna transformación de la materia ${ }^{14}$.

Estos juicios, de un anticientifismo radical en el que resaita un marcado tono moralizador $y$ de autosuficiencia, se explican por un reaccionarismo político en el que se imbricaba un complejo de inferioridad nacional que la impudicia patriotera pretendía enmascarar. Pero, de cualquier modo, una vez señalado esto, debe recordarse --a menudo se olvida - que desde un principio también en la misma Francia la escuela naturalista fue atacada sin paliativos en determinados círculos ultramontanos - los había también en aquel país. En 1868 , al poco de haber publicado Zola Thérèse Raquin, el crítico Ferragus lanzó contra esta novela unos virulentos ataques, dedicándole, entre otras lindezas, el calificativo de "littérature putride", 15 .

Se producía esta coincidencia porque en ambos países había sectores sociales que tenían en común la misma rigidez intelectual propia del pensamiento reaccionario. Para ellos el "otro" era el progreso y la ciencia, y ese "otro" no se hallaba necesaria-

14 A. Prdal y MON, "De la metafisica contra el naturalismo", en Discursos y articulos literarios, Imprenta y Fundación de M. Tello, Madrid, 1887, pp. $48-49$.

${ }^{15}$ Ferragus, "La littérature putride", Le Figaro, 23 de enero 1868. 
mente en "otro" país. La imagen del "otro" habría que centrarla también, por lo tanto, dentro de las fronteras de los dos países. El enemigo, en fin, habitaba también en el mismo espacio geográfico. Al "otro" lo sentían algunos por igual en el interior de la patria, y lo culpaban de poner en peligro las esencias de una tradición cultural autóctona que deseaban inmutable.

En este proceso de positivación se hallaba en juego - como ha observado Arnold Hauser- "una concepción del mundo propia de las ciencias naturales y del pensamiento racionalista y tecnológico sobre el espíritu del idealismo y del tradicionalismo"16. $\mathrm{Y}$ aportando el testimonio de un artículo de Gustave Planche aparecido en la Revue des Deux Mondes, concluía el viejo Hauser -algo aplicable canto a Francia como a España- que "la oposición al naturalismo es una profesión de fe en el orden existente y que, con su repulsa, se rechazan al mismo tiempo el materialismo y la democracia de la época" 17.

Volviendo al caso español, Solange Hibbs-Lissorgues ha tomado, en su artículo "La iglesia católica y el naturalismo", una serie de referencias de la prensa católica española de la segunda mitad del siglo XIX que ilustran los asertos de Arnold Hauser. Esa prensa expresaba su repulsa de la novela de costumbres, pues en ella había "un virus venenoso inficionado en la sociedad por la revolución francesa" (Hibbs-Lissorgues, p. 200). En otro lugar, se aseguraba que las novelas modernas se dirigen " . . a las sensaciones, a los ásperos y funestos instintos que afeminan el alma, rebajan los caracteres y conducen a las naciones a una rápida decadencia" (ibad., p. 200). Por su parte, Antolín López Peláez, arrimaba el ascua a su necesidad de preservar la práctica de un catolicismo tradicional, y prevenía contra la novela naturalista porque era la tendencia "más paladinamente contraria a la doctrina católica" (id., pp. 200201). Se insiste, una y otra vez, en que la novela naturalista era fruto del positivismo filosófico y del materialismo que había llegado de Francia. Según el padre Blanco: "Los españoles no negaron esta vez el asiduo tributo que por costumbre rinden a la moda transpirenaica y siguieron las huellas de Zola con el mismo entusiasmo que en otros días las de Sue, Dumas, Victor Hugo" (id., p. 201). Según Antolín López Peláez, los naturalis-

16 A. Hauser, Historia social de la literatura y el arte, Guadarrama, Madrid, 1972, t. 2 , pp. 82-83.

17 Ibid., p. 86. 
tas profesan: "El método científico que proclama la libertad de pensamiento... Los naturalistas sacuden el yugo filosófico y el teológico". Y a Zola le espetaba: "Ese desdichado que nunca debiera haber nacido no sabe sino rebajar y odiar, causar asco o espanto. El estómago le ha atrofiado el corazón... El vientre, hecho animal, es el puerco... hecho escritor, es Zola"' (id., p. 203). Y a la hora de analizar el éxito de tan nefasta corriente literaria, se decía: “¿Cómo, pues, explicar el favor de que goza la novela naturalista?... Pues porque esta novela es el reflejo del positivismo que domina... en todas las relaciones sociales. . . La numerosa clase proletaria lo acogió con entusiasmo porque... mira en tales libros canonizadas sus utopías y consagrado el culto de la materia" (id., p. 205). Resulta evidente, por tanto, que la defensa de los valores de la ortodoxia católica se hallaba impregnada, mostrando su verdadero rostro, de un discurso ultramontano.

Menéndez Pelayo, de ideología igualmente integrista, arremetió contra el naturalismo, pero se distanció de sus correligionarios, aceptando que, al menos desde el punto de vista de la técnica novelística, era una fuerza innovadora en la medida en que la tal yenía a significar

una protesta, en cierto grado necesaria, contra las quimeras y alucinaciones del idealismo enteco y amanerado; una reintegración de ciertos elementos de la realidad dignísimos de entrar en la literatura, cuando no pretenden ser exclusivos ${ }^{18}$.

Pero Menéndez Pelayo, a continuación, se aprestaba a dcjar bien sentado que él se oponía, consecuente con su catolicismo integrista, a "los cánones científicos del método experimental", pues no entendía que fuera necesario acudir necesariamente a ellos. Así, en el "prólogo" a las obras completas de Pereda, insistía en cuáles eran para él los "pecados de Zola":

Salta a la vista de todo el que haya recorrido sus libros que el patriarca de la nueva escuela, sectario fanático, no ya del positivismo científico, sino de cierto materialismo de brocha gorda, del cual se deduce, como forzoso corolario, el determinismo, o sea la negación pura y simple de la libertad humana, restringe deliberadamente su observación (y aun de ello se jacta) al campo de los instintos y de los impulsos inferiores de nuestra naturaleza, aspirando en todas

${ }^{18}$ M. Menéndez Pelayo, "Don Benito Pérez Galdós", en Estudios sobre la prosa del siglo xix, C.S.I.C., Madrid, 1961, p. 260. 
ocasiones, a poner de resalto la parte irracional, o como él dice, la bestia humana. De donde resulta el que haga moverse a sus personajes como máquinas o como víctimas fatales de dolencias hereditarias y de crisis nerviosas, con lo cual, además de decapitarse al ser humano, se aniquila todo el interés dramático de la novela, que sólo puede resultar de dos voluntades libres, o de la lucha entre la libertad y la pasión ${ }^{19}$.

También en un estudio sobre Galdós, en el que prestó especial atención al primer ciclo de las novelas contemporáneas, observaba Menéndez Pelayo con agrado que en Fortunata y Jacinta había superado la huella del naturalismo francés que se había notado con exceso en La desheredoda. A la altura de 1887, toda aquella corriente francesa que había entrado en España "a banderas desplegadas', por in, ya

ha pasado con la rapidez con que pasan todos los entusiasmos ficticios. Muchos de los que bostezaban con la interminable serie de los Rougon-Macquart y no se atrevían a confesarlo, empiezan ya a calificar de pesadas y brutales aquellas narraciones; de trivial y somera aquella psicología, o dígase psicofísica; de bajo y ruin el concepto mecánico del mundo, que allí se inculca; de pedantesco o incongruente el aparato pseudo-científico con que se presentan las conclusiones del más vulgar determinismo, única ley que en estas novelas rige los actos, o más bien los apetitos de la que llaman bestia humana, víctima fatal de dolencias hereditarias y de crisis nerviosas; con lo cual, además de decapitarse al ser humano, se aniquila todo el interés dramático de la novela, que sólo puede resultar del conflicto de dos voluntades libres, o bien de la lucha entre la libertad y la pasión ${ }^{20}$.

En cuanto a La desheredada, publicada en 1881, en pleno sarampión naturalista, le echa en cara a Galdós que buscara en Francia unos modelos literarios teniendo otros mejores en España. Menéndez Pelayo invitaba a comparar

la tétrica Desheredada con aquella inmensa galería de novelas lupanarias de nuestro siglo XVI, en que quedó admirablemente agotado todo el género (con más regocijo, sin duda, que edificación ni pro-

19 M. Menéndez Pelayo, "Don José María Pereda", en Estudios sobre la prosa del siglo xix, pp. 191-192.

${ }^{20}$ M. Menéndez Pelayo, "Don Benito Pérez Galdós”, ed. cit., pp. 259-260. 
vecho de los lectores), y se verá que algo perdió Galdós con afrancesarse en los procedimientos, aunque nunca se afrancesase en el espíritu $^{21}$.

Llegado a este punto llama no menos poderosamente la atención - hay que subrayarlo, pues se suele pasar por altoque pensadores procedentes de las filas del liberalismo progresista llegaran a coincidir con algunos de los juicios hasta aquí esgrimidos por los prohombres del reaccionarismo decimonónico español. Así, por ejemplo, Gumersindo de Azcárate, quien en un artículo de 1876 hacía estas afirmaciones:

Lo que hace falta es que el positivismo entre por ancho campo, que tras el fenómeno encuentre la esencia, y que no se oponga a la ieligion ni a la metafísica, porque la metafísica y la religión presentan lo eterno y lo absoluto, que no pueden morir ni a manos de las escuelas positivistas ni a manos de ninguna escuela ${ }^{22}$.

Manuel de la Revilla, que en 1876 había protagonizado una dura polémica con Menéndez Pelayo, quien llegó a acusarlo de haber militado siempre "en las filas de la impiedad" 23 , aseguraba en "El naturalismo en el arte" (1879), que la doctrina naturalista pecaba "de exagerada y de exclusiva", reducía el arte "a límites estrechos y arbitrarios", se complacía solamente "en lo vulgar, en lo ruin y lo pequeño", gozaba "de revolcarse sobre el fango" $y$, en suma, que únicamente le interesaba representar "lo vil y lo repugnante". Para Manuel de la Revilla.

la nueva escuela se complace en revolver las inmundicias de la vida y sacarlas a público teatro en sus más soeces y repulsivos detalles, haciendo de lo que sólo en secundario término puede admitirse en la pintura, el asunto capital del cuadro. Hay en esto cierto alarde de atrevimiento un tanto pueril que se parece al empeño que el niño pone en hacer todo lo que se le señala como impropio e incon-

21 Ibid., p. 262.

${ }^{22}$ G. DE AzCÁrate, "El positivismo en el Ateneo", Revista Contemporánea, 15 de mayo 1876 .

${ }^{23}$ M. Menéndez Pelayo, "Mr. Masson, redimuerto", en La polémica de la ciencia española, eds. E. y E. García Camarero, Alianza Editorial, Madrid, 1970 , p. 242. Sobre la polémica entre M. de la Revilla y M. Menéndez Pelayo, véanse esp. las pp. 201-307. 
veniente. El amor al escándalo y a la notoriedad entra por mucho en estas audacias de los enfants terribles del naturalismo ${ }^{24}$.

Y refiriéndose específicamente a L'Assommoir, la novela de Zola que contribuyó de manera decisiva a divulgar la escuela naturalista en España, fue así de contundente respecto de la novela y del movimiento literario del que esa novela había sido erigida portaestandarte:

Menosprecio de la forma, olvido del gusto, afectada desnudez en la pintura, artificiosa grosería del lenguaje, marcado empeño en llevar al arte únicamente lo que hay de feo, vil y repulsivo en la realidad; he aqui fundarentalmente errones do la escuela naturalista.

Es indudable que si las exageraciones del naturalismo prevale cieran el arte caería en profundo abismo... El abandono de toda idealidad, el menosprecio sistemático de la forma, la afición a hacer alarde de originalidad y de destreza en la pintura de lo feo, lo repugnante y lo grosero, engendrarían un arte prosaico, pedestre, falto en absoluto de todo elemento ideal y poético, révestido de formas rudas, en el cual el goce estético quedaría reducido a la admiración que produjera la habilidad del artista. Si tales extravíos alcanzasen el triunfo el arte no tendría razón de ser ${ }^{2.5}$.

Pico de la Mirándola, que en una de sus "Cartas parisien" ses", publicada el 15 de abril de 1877 en La Ilustración Española y Americana, hizo una breve historia de la evolución de la novela en el siglo xx, terminó coincidiendo con Manuel de la Revila en su apreciación del naturalismo:

A los románticos siguieron los realistas, y de este tronco, cuyas raices estaban apegadas a la tierra, han ido brotando diversas

${ }^{24}$ M. DE LA Revilla, “El naturalismo en el arte", en Krausismo: estética y literatura, ed. J. López Morillas, Labor, Barcelona, 1973, pp. 179-180.

${ }^{25} \mathrm{Ibid}$., p. 183. Por contra, ArTUro BeL-AsA, en un artículo sobre $L ' A s$ sommoir de Zola y La Fille Elisa de Edmond Goncourt, publicado el 2 de abril de 1877 en El Imparcial, salía en defensa de esta literatura con estos argumentos: "Jesús predicaba, pero azotaba a los mercaderes, ¿por qué los miles de hombres que pactan con la prostitución, que la halagan, que están familiarizados con el cieno revuelto de Edmond Goncourt, se han de mostrar encolerizados de que así se saquen al viento semejantes pestilencias? Para curar el mal lo primero es decubrirlo. Y éste es el verdadero carácter del realismo que por todas partes se advierte e invade a la sociedad. Comienza a verse despreciada la hipocresía, a verse honrada la franqueza. Bendito sea el cambio 
ramas que se inclinan con creciente voluptuosidad hacia las ciénegas y los pantanos, cual si fuese su suprema aspiración el abrazar el lodo.

Los escritores que se apellidan a sí propios naturalistas, y cuyas flamantes producciones en prosa y en verso se complacen en la fotografía de todas las podredumbres carnales, son la última manifestación de este desenfrenado desgajamiento literario.

Lo que producen estas rebeliones y este soez enfatuamiento, que mueve a muchos literatos a no reconocer más regla ni precepto que los delirios que su fantasía aguijoneada por el afán del estrépito y el desprecio de toda autoridad intelectual, el catálogo de las librerías lo dice claramente. Jamás las letras francesas habían podido imaginarse que caerían en tales sumideros ${ }^{26}$.

En parcidos términos mostraban su resistencia al naturalismo Emilia Pardo Bazán o incluso - como veremos-Clarín. La Condesa, en el "prefacio" a Un viaje de novios (1881), ponía reparos al credo de "la escuela de noveladores franceses que enarbola la bandera realista o naturalista" porque le parecía "errada y torcida en bastantes aspectos" 27 . Si por un lado elogiaba la técnica de "la observación paciente, minuciosa, exacta, que distingue a la moderna escuela francesa", mostraba su desacuerdo "con, la elección sistemática y preferente de asuntos repugnantes o desvergonzados, la prolijidad nimia, y a veces cansada, de las descripciones...", pero, con todo, lo que le parecía más inadmisible del naturalismo era la concepción "filosófica" de Zola, "sus doctrinas deterministas, fatalistas y pesimistas", pues "por esos cerros ningún católico podía seguirle"'28.

El rechazo, total o parcial, del naturalismo, fue acompañado de una toma de conciencia nacionalista. Progresivamente se fue argumentando que la cuna del realismo y del naturalismo no estaba en Francia sino en España. Había que sacudirse de encima, por tanto, lo que entendían como el oprobio de la dependencia cultural de Francia.

Pardo Bazán, que en La cuestión palpitante había reconocido que "nosotros, los de acá del Pirineo, [somos] satélites - mal

que así restablecerá el imperio de la verdad" .

26 Plco de la Mirándola, "Cartas parisienses", La llustración Española y Americana, 15 de abril 1877

27 E. PARDO BAZÁn, en su prólogo a Un viaje de novios, en Obras completas, Aguilar, Madrid, 1972, t. 2, pp. 571-572.

28 E. PARdo BAzÁN, "Coletilla a La cuestión palpitante", en Obras completas, t. 2 , p. 658 . 
que nos pese- de Francia" 29 , argüía, en el prefacio a Un viaje de novios, que el "realismo nacional" era superior al francés:

¡Oh, y cuán sano, verdadero y hermoso es nuestro realismo nacional, tradición gloriosísima del arte hispano! ¡Nuestro realismo, el que ríe y llora en La Celestina y el Quijote, en los cuadros de Velázquez y Goya, en la vena cómico-dramática de Tirso y de Ramón de la Cruz! ¡Realismo indirecto, inconsciente, y por eso mismo acabado y lleno de inspiración; no desdeñoso del idealismo y gracias a ello, legítima y profundamente humano, ya que como el hombre reúne en sí materia y espíritu, tierra y cielo. Me enorgullezco de las facultades de nuestra raza, al par que me aflige el mezquino premio que logran los ingenios de España, y me abochorna la preferencia vergonzosa que tal vez concede la multitud a rapsodias y versiones pésimas de Zula, habiendo en España Galdós, Peredas, Alarcones... ${ }^{30}$.

También Galdós salió en defensa de la originalidad e independencia de la novela española. En el prólogo a El sabor de la tierruca aseguraba que el naturalismo de Pereda estaba "inspirado casi exclusivamente en corrientes nacionales". Y haciendo alusión velada a la escuela naturalista francesa, decía que Pereda había hecho

prodigios cuando aún no habían dado señales de existencia otras maneras de realismo, exóticas, que ni son exclusivo don de un célebre escritor (Zola, evidentemente), ni ofrecen, bien miradas, novedad entre nosotros, no sólo por el ejeniplo de Pereda sino por las inmensas riquezas de este género que nos ofrece la literatura picaresca $^{31}$.

Galdós no andaba descaminado, ni mucho menos, sobre todo si pensamos en algunos cuentos de Pereda, como "La leva', pero sus juicios son desmedidos y, pensando en el conjunto de la obra perediana, inexactos. Pero, además, a Galdós lo guiaban motivaciones que poco tenían que ver con la objetividad de sus juicios críticos. Algo que, comentando este prólogo, se encargó de señalar Pattison en El naturalismo español:

${ }^{29}$ E. Pardo BazÁn, La cuestión palpitante, en Obras completas, t. 2, p. 586.

${ }^{30}$ E. Pardo BazÁn, prólogo a Un viaje de novios, ed. cit., pp. 572-573.

${ }^{31}$ B. Pérez Galdós, "Prólogo a El sabor de la tierruca", en Ensayos de crítica literaria, ed. L. Bonet, Península, Barcelona, 1972, pp. 166-167. 
El orgullo de don Benito se lisonjea al notar que España no va a la zaga de la nación vecina; no obstante, para gozar plenamente de este triunfo de las letras españolas, será necesario que Pereda se reconozca competidor de Zola, es decir, como naturalista. De otro modo, España tendrá que admitir otra vez la primacía de Francia. Así Galdós, espera introducir suavemente a Pereda en la secta de los naturalistas moderados, de que él es el jefe reconocido ${ }^{32}$.

En el prólogo a La Regenta había vuelto Galdós a insistir en que los novelistas naturalistas españoles debían muy poco a los franceses, pues

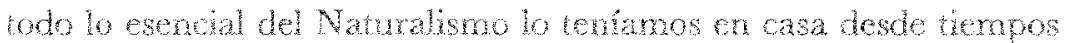
remotos, y antiguos y modernos conocian ya la soberana ley de ajustar las ficciones del arte a la realidad de la Naturaleza y del alma, representando cosas y personas, caracteres y lugares como Dios los ha hecho. Era tan sólo novedad la exaltación del principio y um cierto desprecio de los resortes imaginativos y de la psicología espaciada y ensoñadora ${ }^{33}$.

Es más, el naturalismo francés, según argumentaba Galdós, había introducido variantes empobrecedoras en el naturalismo de raigambre española (la picaresca, Cervantes, etc.), al que tanto franceses e ingleses debían. Y $Y$ es que, señalaba con tino Galdós, al naturalismo de Zola le faltaba el humor, "la forma más genial de nuestra raza"'34. Así pues a los novelistas de su generación les comespondía recuperar ese rasgo distintivo. Los franceses, venía a decir Galdós, habían tomado de España el naturalismo y lo habían puesto de moda, porque "Francia, poderosa, impone su ley en todas partes" y "nosotros no somos nada en el mundo"35. Pero, precisamente debido a ello, les correspondía a los novelistas españoles volver a la tradición española y potenciar el humor, ese rasgo distintivo que no habían sabido incorporar a su escritura los franceses.

Galdós reaccionaba, de un lado, ante lo francés por un prurito nacionalista $y$, de otro, señalaba la constante que mejor define su arte de novelar, la ironía cervantina:

32 W. T. Pattison, El naturalismo español, Gredos, Madrid, 1965, p. 71.

33 B. Pérez Galdós, en su prólogo a La Regenta, apud la ed. de G. Sobejano, Castalia, Madrid, 1981, p. 83.

${ }^{34}$ Ibid., p. 84.

${ }^{35}$ Loc. cit. 
Al volver a casa la onda, venía radicalmente desfigurada... el Naturalismo cambió de fisonomía en manos francesas: lo que perdió en gracia y donosura, lo ganó en fuerza analítica y en extensión, aplicándose a estadios psicológicos que no encajan fácilmente en la forma picaresca. Recibimos, pues, con mermas y adiciones (y no nos asustemos del símil comercial) la mercancía que habíamos exportado, y casi desconocíamos la sangre nuestra y el aliento de alma española que aquel ser literario conservaba después de las alteraciones ocasionadas por süs viajes. En resumidas cuentas: Francia, con su poder incontrastable, nos imponía una reforma de nuestra propia obra, sin saber que era nuestra; aceptámosla nosotros restaurando el Naturalismo y devolviéndole lo que le habían quitado, el humorismo, y empleando éste en las formas narrativa y descriptua conome a la tradión cervantesca 36 .

Efectivamente, a Cervantes, como es bien sabido, se le consideró en numerosas ocasiones un antecedente de la escuela natu. ralista. Pero en lo tocante a este extremo, merece la pena recordar que Juan Mañé y Flaquer, en el ya citado prólogo a Nora, la novela de la baronesa Von Brackel, llegaba a estas conclusiones:

Como todos los aventureros que logran abrirse camino, como todos los parvenus, después de adquirir nombre y provecho, Zola quiso justificar su procedimiento, y hasta ostentar noble abolengo. Entonces vieron la iuz todas esas teorías, a la cual más sofística, de que el arte moderno debe ser sobre todo humano, y se citó en su apoyo el ejemplo de todas las literaturas y de los autores más conspicuos. Hasta a nuestro pobre Cervantes, tan desgraciado en vida y tan calumniado en muerte, se le han removido los huesos para atribuirle el crimen de ser uno de los progenitores del moderno realismo 37.

El prurito nacionalista aflora igualmente en otros autores. Juan Valera, en Apuntes sobre el nuevo arte de escribir, después de ponderar la significación histórica de obras como el Qü̈jote, el Amadís o La Celestina, hacía estas reflexiones que en el fondo equivalían a reconocer que el país había perdido protagonismo:

Habiendo, pues, mostrado España tan notable aptitud para las novelas, natural es que aspiremos a escribirlas de nuevo, con la

36 Loc. cit.

37 Ed. cit., p. xi. 
misma abundancia y buen éxito que los ingleses y franceses... [Pero] ¡Infeliz del autor que no escribe según la moda! Ahora bien: la moda, por la superior importancia de París y Londres, y por el poder de Francia e Inglaterra, viene de dichas capitales. Todo autor, por consiguiente, se halla en la forzosa disyuntiva de escribir fuera de moda, o ser arrendajo de los autores extranjeros, aceptando teorías, métodos y estilos exóticos, por extranjeros que sean... El gusto, el tono, la manera, como quiera llamarse, viene de París. Forzoso es aceptarlo, si no queremos pasar por retrógrados, ignorantes, oscurantistas y tontos. Así fuimos seudoclásicos a lo Boileau, hasta el año treinta y tantos; luego románticos a lo Víctor Hugo, y así tenemos que ser ahora naturalistas a lo Zola ${ }^{38}$.

La recuperación de tal protagonismo se intentó por medio de una declaración de autonomía de la novela española, que era, claro está, un simple mecanismo de autodefensa. Había que volver a escribir la historia, darle un giro marcadamente nacionalista. Se echaba así mano de argumentaciones ad hoc, sin importar demasiado su justeza o propiedad. Ortega y Munilla, escribía, en 1887, en El Imparcial:

En España el arte naturalista ha caído sobre buena tierra. En primer lugar, porque aquí la novela clásica había dejado simientes de la mejor casta, y además porque ha acometido, en virtud de secreto designio de la Providencia, que habiendo desaparecido de la librería el género anticuado y brutal engendro novelesco por entregas, florecieron al mismo tiempo en el jardín de nuestro Olimpo, los Galdós, los Peredas, los Pardo Bazán y Palacio Valdés, Picón y Alas...

Hemos tenido, pues, novelas naturalistas sin tener que avergonzarnos del exceso que les duele a los franceses, y podemos presentar en la colección nacional una docena de libros que compitan con los mejores de Francia y aun que les aventajen ${ }^{39}$.

Esta y otras declaraciones parecidas de independencia en torno a la presumida independencia del naturalismo español solían ir acompañadas de duros ataques contra Zola. Como ha dicho Pattison: "El supremo pontífice francés se ha convertido en una

${ }^{38} \mathrm{~J}$. VALERA, Apuntes sobre el nuevo ante de escribir novelas, en Obras completas, Aguilar, Madrid, 1961, t. 2, pp. 618-619.

${ }^{39}$ Cf. W. T. PatTison, op. cit., p. 142. 
especie de Lucifer y sus adictos españoles ya no pueden comulgar con él" 40.

Manuel Cañete reseñó en 1881 en la Revista de Madrid la comedia de Celerino Palencia, El guardián de la casa, en la que una madre había terminado

extraviada por la literatura malsana que apellidándose realista no abarca la realidad completa ni la retrata con exactitud, sino que se deleita en reproducir exageradamente las inmundicias sociales, admira con ciega admiración los repugnantes cuadros que traza en La Taberna el grosero naturalismo del novelista Zola, y emplea el tiempo que debiera consagrar a cumplir sus deberes, en escribir una novela titulada El Bodegón 4 .

Esa comedia, apuntando un vez más a Francia, terminaba con estos versos, que muestran cómo la susodicha obra tenía una intención inequívocamente panfletaria:

Si destroza el corazón

si pureza y candor quita, una y mil veces maldita esa civilización ${ }^{42}$.

La misma finalidad de desprestigiar al naturalismo perseguía la crónica, entre macabra y folletinesca, aparecida el 11 de octubre de 1875 en la sección "La Semana en París" de Los Lunes de El Imparcial. Esa crónica melodramatizaba, como demuestra la utilización del diálogo y la apostilla final, la historia de un niño de cinco días que había sido ahogado por otro niño de doce años:

Berthelot se asesoró, antes de cometer su crimen, con otro chico de edad de catorce años.

- ¿Sigues en casa de Boissinot? -le preguntó éste.

- Sí, respondió Berthelot.

- Parece que son muy desdichados. Están cargados de familia y tu ama va a dar a luz de nuevo en estos días. ¿No podrías ahogar a alguno de los pequeñuelos? Eso le aliviaría.

Berthelot prestó atención al consejo, y a la primera ocasión propicia estranguló al recién nacido.

${ }^{40}$ Loc. cit.

${ }^{41}$ Cf. M. López-SANz, Naturalismo y espiritualismo en la novelística de Galdós y Pardo Bazán, Pliegos, Madrid, 1985, p. 25.

${ }^{42}$ Loc. cit. 
$\mathrm{Y}$ bien, este muchacho merece un premio de lógica. Una vez admitida la moral positivista y la felicidad terrestre como suprema meta, el fin justifica los medios ${ }^{43}$.

Los ataques contra Zola-Lucifer llovían por todas partes, hasta por donde menos uno podía esperarlos. Así, por poner otro ejemplo, Pedro Muñoz Peña escribía en 1888, en un libro-reseña sobre Fortunata y Jacinta:

Porque no se crea que el naturalismo de Pérez Galdós convierte el arte en albañal inmundo de las miserias y flaquezas humanas, ni de sus novelas resulta ese sabor amargo, hiponcondríaco y pesimista, gue conduce a los lectores a abonecer la vida y la sociedad. el mundo y haturaleza. . siro que por el contrario el naturalismo de nuestro novelista es pintura de lo real, es observación analitica del hombre y de la naturaleza, pero pintura y observación artística y por tanto bella, y en este sentido creemos que el novelista español es mucho más aceptable que los mismos iniciadores y propagandistas de este carácter y nota contemporánea de la novela, y aun superior - ¿por qué no lo hemos de decir? - a Zola mismo que de apóstol se ha convertido en sectario del naturalismo... ${ }^{44}$.

Hacia 1887 se vislumbró en el horizonte la posibilidad de emanciparse de la influencia francesa. Se descubrió la literatura rusa, y de ella sobre todo a Tolstoi y Dostoievski. Emilia Pardo Bazán leyó en el Ateneo de Madrid la serie de conferencias La revolución y la novela en Rusia y Galdós tituló un capítulo de Fortunata y Jacinta "Naturalismo espiritual". Se reconoció que a unos específicos hechos sociales e histónicos correspondía una determinada producción cultural. En las estructuras españolas difícilmente podía permear la mentalidad positiva que tanto auge había alcanzado en Francia y que, entre otras cosas, estaba en la base de la escritura naturalista, porque la burguesía española era apenas existente. España, en suma, estaba más cerca de Rusia que de Francia. El espiritualismo de la novela rusa que se acababa de descubrir estaba, según se insistía, más acorde con España, era más congruente con su situación socio-histórica. Así, además, se pretendía ahuyentar del horizonte el fantasma del materialismo, al que los novelistas españoles, hasta los más

43 "La Semana en París", Los Lunes del Imparcial, 11 de octubre 1875.

${ }^{44}$ P. MUÑoz Peña, Juicio crítico de "Fontunata y Jacinta", Imprenta y Librería Nacional y Extranjera de H. Rodríguez, Valladolid, 1888, pp. 12-13. 
progresistas, veían con malos ojos. Rusia presentaba a los españoles la anhelada oportunidad de emanciparse de Francia. Pero no se había caído en la cuenta de que el mismo proceso había empezado a cundir en Francia. Por otra parte, no deja de ser irónico que Pardo Bazán, en sus conferencias del Ateneo, hubiera utilizado como falsilla el libro de Vogüé, Le Roman russe. Y, para colmo, Pardo Bazán no cita ese libro en la bibliografía que incorporó cuando aparecieron en libro esas conferencias. La dependencia cultural de Francia, a pesar de los pesares, continuaba teniendo un indiscutible protagonismo.

Tomás Tuero, en La Iberia (1887), había tomado muy buena nota de la situación a la que se había llegado en España:

La prueba de que el naturalismo no nos llegó al alma, es que hoy nadie habla del asunto... iLa experimentación! YYa nadie se acuerda de palabreja semejante!... Pero en la actualidad, calma chicha. ¡Adiós medio ambiente, selección, herencia! Naturalistas e idealistas se metieron en sus agujeros respectivos, oficinas del Estado generalmente, y no hay ya pólvora en el aire ni en la pluma pasión.

Bien sabe Dios que el asunto quedó a medio resolver, y que, al paso que íbamos, no se veía solución probable. Por lo mismo no debió abandonarse nunca la polémica; nada más propio de nuestro carácter que estas batallas contra molinos de viento y contra todo lo que viene de Francia ${ }^{45}$.

Las causas explicativas de esta situación hay que buscarlas, como queda apuntado al comienzo de estas páginas, en la distancia que existía en el siglo xix entre las estructuras político-sociales de Francia y de España. Algo que, curiosamente, también vio Pardo Bazán, aunque le faltara la apropiada perspectiva ideológica para poder calar hondo en el sentido de sus intuiciones. En sus conferencias sobre La revolución y la novela en Rusia había llegado a conclusiones como las que cito a continuación, cuyo alcance había reducido, pues lo que pretendía era simplemente apartarse del modelo francés y justificar la adhesión a la novela rusa, cuya sociedad, al igual que la española, estaba muy lejos de Francia, revolucionaria en filosofía, en literatura y - ahí era donde más dolía - en política: 
La novela es espejo clarísimo, expresión cabal de las sociedades; no me cansaré de repetirlo, y es fácil comprobarlo con sólo frjarse en el estado actual de la novela en Europa... En Francia, donde hoy, a pesar de los esfuerzos de la escuela espiritualista y ecléctica, han prevalecido las tradiciones de la Enciclopedia, el frívolo materialismo sensualista, la novela sigue ese camino; y sin que sea mi ánimo entonar el famoso estribillo de la canción de Béranger:

$$
\begin{aligned}
& C \text { 'est la faute de Rousseau } \\
& C \text { 'est la faute de Voltaire }
\end{aligned}
$$

aseguro que el animalismo, el determinismo materialista, el pesimismo, el decadentismo, pueden explicarse mediante la filiación de los grandes escritores del siglo XVIII, no tanto por su influjo literario, cuanto porque la sociedad que estudian los novelistas actuales es hija de la Revolución francesa, y ésta de la Enciclopedia ${ }^{46}$.

En Francia también se había mciado, después de que Zola publicara en 1887 La Terre, el proceso de ruptura dentro de las filas del naturalismo. Muchos autores, progresivamente, se fueron adhiriendo a la nueva corriente espiritualista. Lo irónico es que en Francia, tiempos atrás, en plena euforia naturalista, se había solido calificar a los novelistas españoles, en un tono despectivo, de "espiritualistas". Lo cual había abierto un curioso debate. Porque muchos críticos y novelistas españoles - no deja de ser paradójico-, antes de declararse abiertamente partidarios de la nueva boga espiritualista, que tenía como popes más destacados a Renán, Guyau, Desjardins y la novela rusa, habían defendido que eran auténticamente naturalistas y, por consiguiente, mal comprendidos por la crítica francesa.

Zola, en una entrevista con Rodrigo Soriano, aparecida en La Época, no ocultaba su "extrañeza de que la señora Pardo Bazán sea católica ferviente, militante, a la vez que naturalista; y me lo explico sólo por lo que oigo decir de que el naturalismo de esa señora sea puramente formal, artístico y literario" 47.

Albert Savine, el traductor al francés de La cuestión palpitante, concluía en el folleto Le naturalisme en Espagne. Simples notes (1885) que, a diferencia del francés, el naturalismo español había sido "toujours spritualiste, souvent même catholique, et par conséquant, jamais pessimiste" 48 .

${ }^{46}$ E. Pardo BazÁn, La revolución y la novela en Rusia, en Obras completas, t. 2, pp. 875-876.

47 Apud E. Pardo Bazán, Obras completas, t. 2, p. 1033.

${ }^{48}$ W. T. Pattison, op. cit., pp. 123-124. 
F. B. Navarro, en un artículo-reseña sobre La Regenta, publicado en 1886 en la Revue Britannique de París, refutaba la opinión de Albert Savine y de otros críticos franceses que calificaban al naturalismo español de espiritualista. Navarro, después de repasar la producción novelística española, seguía sin comprender

qué es lo que ciertos críticos franceses dedicados a la literatura española consideran naturalismo espiritualista. ¿Hay que declararse materialista en filosofía, determinista en fisiología, ateo en religión, para entrar en las filas de la escuela literaria naturalista? ¿No existe, no puede existir, un espíritu naturalista, espíritu de observación sabiamente aplicado, fuera de la estrecha intransigencia apriorística respecto a toda positiva creencia? Si es así, tendríamos que hallar un nombre más ajustado a la escuela cuyo objetivo es la representación de la naturaleza, por la simple razón de que nada en la naturaleza debería poder escapar a los procedimientos artísticos de la reproducción, lo mismo en literatura que en pintura. En Italia el naturalismo se llama verismo: quizá sea un término más adecuado.

Los que prefieren creer en la positiva existencia de dos escuelas literarias en España son víctimas inconscientes de un espejismo cuyas proporciones la distancia se encarga de exagerar. A los mejores críticos españoles jamás se les ha ocurrido calificar de espiritualistas las creaciones de Zola, de los Goncourt, de Flaubert incluso, por no decir de Balzac. Sin embargo, ¿qué no se hubiera dicho del Abbé Mouret, del idilio de La Conquête de Plassans, de Madame Bovary y de tantos otros, si hubiesen visto la luz en España? (TINTORÉ, pp. 215-216).

Todas estas reflexiones venían a cuento porque Navarro temía que La Regenta sería tildada en Francia de espiritualista,

y ello sencillamente porque a la vez que un análisis psicológico sometido al procedimiento de examen fisiológico defendido por Zola, es también un estudio del misticismo histérico encarnado en su protagonista. Pero habría que ignorar absolutamente todo sobre el autor de la La Regenta para considerarlo espiritualista o para olvidar que fue uno de ios primeros escritores españoles que defendió y admiró al moderno novelista francés (ibid., p. 216).

Con todo, La Regenta pasó prácticamente inadvertida en Francia, donde por cierto se ha traducido con gran éxito pero tardíamente, en 1987.

En cuanto a Clarín, el crítico que más "había predicado y defendido" el naturalismo francés y que con su novela La Regenta 
más había hecho "en pro del naturalismo" (id., p. 93), no deja de ser irónico que Zola, en una entrevista que le hicieron en 1891 no conocía "ni tan siquiera el nombre de nuestro novelista" (id., p. 64). Pero dos años más tarde, Gómez Carrillo recogía en Sensaciones del Arte estas palabras de Zola: "Savine m'a aussi parlé de votre Clarín... mais il parait que c'est un des critiques que nous ont le mieux étudié en Europe!"' (loc. cit.).

Volviendo a la vertiente espiritualista de la novela española del xIX, resulta difícil rebatir que no fuera, de una u otra forma, una constante dominante, incluso entre quienes se adhirieron a las tesis naturalistas. Gómez Ortiz, en sus estudios literarios sobre el naturalismo de 1884, supo expresar con concisión y exactitud la presencia de unas traisteriosas y yagas aspiraciones" anímicas, unas constantes que explican la heterodoxia del naturalismo español:

son para el arte de inestimable provecho estas misteriosas y vagas aspiraciones que viven en el fondo del alma, estas ansias y anhelos que con nada satisfacen su devorante sed; estas inexplicables alegrías que nacen al contacto de una meditación feliz y estos quebrantos ideales, que acaso envía una Providencia invisible; por esto tienen cuerpo y realidad estos temores y estas esperanzas no entendidas por los naturalistas, pero se agitan y mueven, se agrandan y disminuyen dentro del espíritu al impulso de un soplo desconocido que en movimiento incesante las recoge o precipita, cual la atracción del astro de la noche que, al provocar el flujo o reflujo de los mares, estrella con inclemente furia sus aguas en las quebradas costas, o las deshace en espuma entre suaves arenas de la playa.

En la vida del arte, como en la de la naturaleza, $\tan$ real es la suspicacia de Sancho como la locura del andante y simpático caballero de Dulcinea ${ }^{49}$.

No se olvide además que Gómez Ortiz había concluido sus estudios con estas palabras:

Los idealismos de la forma han desaparecido, porque la belleza sola no es nada.

Hay que renunciar, en beneficio de las sociedades, al placer de las literaturas pasadas: tenemos que abandonar lo bello del espiritualismo; renunciar a las creaciones fantásticas, ante la nueva lite-

${ }^{49}$ E. Gómez Ortiz, El naturalismo. Estudios literarios leidos en el Ateneo de Madrid, Establecimiento Tipográfico, Madrid, 1882, p. 54. 
ratura que se inspira en las luchas diarias de la humanidad, que tiene por destino el progreso y por aspiración la cultura ${ }^{50}$.

Como había dicho el primer traductor al español de Nana en un breve prólogo, en donde pretendía ijustificar la necesidad de traducir a Zola y a la vez salía en defensa de los más posibles ataques (no firmó la traducción, sin duda, por ese motivo) de que iba a ser objeto porque aquí "sólo consentimos el arte eunuco":

En nuestra España hoy es preciso luchar en todos los terrenos si queremos que la distancia que nos separa del mundo, propiamente dicho civilizado, no sea desconsoladora por lo grande. En política, en religión, en economía, en arte, en literatura muy especialmente, es preciso combatir con entusiasmo, y con la pasión que lo engendrá, contra la reacción descocada, bárbara y potente, que nos asfixia y que nos devora ${ }^{51}$.

Clarín, a pesar de lo mucho que admiraba a Zola, repitió en no pocas ocasiones que no estaba totalmente de acuerdo con aspectos esenciales del naturalismo. Así, en "Del naturalismo", ensayo publicado en La Diana en 1882, consideraba equivocada la tesis naturalista de que el arte debía ser,

como desideratum por lo menos, ciencia exacta de observación que ayude, con su modo peculiar de estudiar el mundo, el trabajo analítico de la ciencia. ¿Y qué ciencia es ésta? Según Zola, la ciencia del positivismo, la negación de la metafísica, de las fuentes superiores de conocimiento ${ }^{52}$.

En este mismo ensayo, después de negar que fuera posible establecer una relación directa entre el arte y la ciencia - lo cual equivalía a confundir el arte con el positivismo-, calificaba a éste de "escuela estrecha, cerrada y de muy pocos sólidos fundamentos..." ${ }^{53}$. En 1881, en la crítica del drama de Echegaray, Haroldo el normando, repetía que "el naturalismo como escuela exclusiva de dogma cerrado, yo no lo admito; yo no soy más que

${ }^{50}$ Ibid., p. 192.

51 'Z"', "Al lector", en É. ZOLA, Nana, Alfredo de Carlos Hierro, Madrid, s.f., p. 11.

${ }^{52}$ Leopoldo Alas, Teoria y crítica de la novela, ed. S. Besser, Laia, Barcelona, 1972 , p. 125

${ }^{53}$ Ibid., p. 125. 
un oportunista del naturalismo; creo que es una etapa propia de la literatura actual'"54. En 1883, en el prólogo a La cuestión 'palpitante, volvía a decir, con casi las mismas palabras - le aterraba verle las orejas al lobo naturalista-, que la escuela de Zola no era "solidaria del positivismo" ni "una doctrina exclusiva, cerrada... Es más bien un oportunismo literario. . . la literatura más adecuada a la vida moderna...' (TorREs, pp. 134 y 135). Finalmente, en 1901, en el prólogo a Trabajo, recordaba:

En España, tuve el honor de ser el primero, allá en mi juventud, casi adolescente, que defendió las novelas de Zola, de entonces (para mí las mejores de las suyas), y hasta su teoría naturalista, con reservas, como un oportunismo, pero sin admitir la supuesta solidaridad del naturalismo estético y del empirismo filosófico (Trabajo, p. 149).

En Clarín existía, por tanto, desde un primer momento, la tendencia a aceptar aspectos concretos del naturalismo, principalmente de carácter estético, pero siempre dejando muy patente que había que desvincular lo estético de cualesquiera posibles lazos con la doctrina positivista. En la década de 1890, esos lazos que ya no se atrevió Clarín a cuestionar, potenciaron la ruptura abierta de Clarín con el naturalismo, al que, como veremos, en el mejor de los casos, pretendió enmendarle la plana, prácticamente acusando a Zola de haberse apartado de la auténtica doctrina naturalista.

En Clarín, con el paso de los años, fue cristalizando una en él siempre latente religiosidad. Se trató muy probablemente, como indica Lissorgues, de una suma de circunstancias diversas. Por un lado, la necesidad de Dios la fue sintiendo como una "exigence vitale", como la busca "de la cohérance du monde après les désillusions historiques" 55 . Y luego estaba el problema de su grave enfermedad. En 1898 su salud había decaído; agravada a finales de 1900 , todavía tradujo Trabajo ${ }^{56}$. Como ha señalado Mariano Maresca, la crisis religiosa de Clarín se acentúa -así como su distanciamiento del positivismo- en estos años últimos de su vida:

${ }^{54} I d .$, p. 106.

55 Yvan Lissorgues, La pensée philosophique et religieuse de Leopoldo Alas "Clarin", 1875-1901, Éditions du C.N.R.S., Paris, 1983, p. 331.

56 Juan antonio Cabezas, "Clarín". El provinciano universal, Austral, Madrid, 1962, pp. 214-217. 
La coincidencia es objetiva: mientras la decadencia física se agudiza, más cerca está el final de la orfandad espiritual. Lo cual admite una lectura paradójica: Clarín logra la seguridad de haber llegado a una posición sólida en su relación con Dios - que es ya el único problema importante- justamente cuando más aguda es su esclavitud a la determinación fisiológica que supone la "enfermedad". Ocurre, pues, como si para saber encontrar la forma auténtica de situarse ante Dios hubiera antes que retirar la energía de ese combate temporal con la materia y la historia en el que buscamos soluciones que siempre serán insuficientes para nuestro destino fundarrental, porque los problemas que en ese ámbito se plantean son, en principio, problemas falsos. No resulta fácil eludir el sentido de este happy end, porque lo que hay en el fondo no es otra cosa que el problema de la religosidad de Clarin, que sin duda es el Iundamental, por cuanto la religión fue la religión del pensamiento a la que Alas fue reconduciendo - en busca precisamente de paz - todo lo que antes ideó y dijo, ignoró y calló, amó y tuvo, deseó y envidiós7.

Clarín se decantó abiertamente, en un escrito de 1895 al que en seguida me referiré, por una concepción del mundo esencialmente espiritualista y por tanto, idealista. Sin duda, hay unas marcadas diferencias de Clarín con Alarcón, Nocedal y otros ilustres ultramontanos decimonónicos. Pero, en lo esencial, su espiritualismo y su idealismo, por muy heterodoxo que fuera ${ }^{58}$, lo acercó ideológicamente a ellos. Resulta patético que un hombre de su bagaje intelectual y humano hubiera caído en tamaña contradicción. Sin embargo, su proceso evolutivo, por mucho que sus apologistas lo intenten enmascarar o relativizar, siguió ese curso. Que así fuera se explica, en última instancia, por la presencia de unas estructuras mentales solidificadas, cuyo protagonismo venía condicionado por unos factores socio-históricos, a los que ni intelectuales como Clarín o Galdós, dos insignes y destacados representantes de la burguesía liberal española, lograron escapar.

Como ya queda señalado, Clarín expresó en 1895 con una inequívoca claridad cuál iba a ser en adelante su credo ideológico y literario. En el prólogo a Cuentos morales - fechado también en 1895 - recordó que en sus invenciones literarias lo principal

${ }^{57}$ Mariano Maresca, Hipótesis sobre Clarín. El pensamiento crítico del reformismo español, Diputación Provincial, Granada, 1985, p. 314.

${ }^{58}$ Cf. el cap. 5 del libro ya citado de Yvan Lissorgues, La pensée philosophique... 
nunca había sido "el mundo exterior, las vicisitudes históricas y sociales, sino el hombre interior, su pensamiento, su sentir, su voluntad"' (apud Ramos-GAscón, p. 98). Después, añadía que si en su juventud le había preocupado sobre todo la mujer, "el platonismo amoroso", en la edad madura, la idea capital que más le llenaba era "la del Bien, unida a la palabra que le da vida y calor: Dios" (Ramos-Gascón, p. 99). Finalmente, después de afirmar: "Yo soy, y espero ser mientras viva, partidario del arte por el arte, en el sentido de mantener como dogma seguro el de su sustantividad independiente" (ibid., p. 98), y de insistir en que sus "ensueños de la Idea Divina, ya empezaron cuando empezaban mis ensueños amorosos, de don Juan por dentro...' (id., p. 99), declaraba que su nueva leyenda era la "leyenda de Dios", que, con el paso del tiempo, se había "engrandecido, fortificado y depurado [sic $]$ ", apostillando: "espero que me acompañe hasta la hora solemne, pero no terrible, de la muerte"' (loc. cit.).

No ha de sorprender, por consiguiente, que, a partir de este momento, salieran a un primer plano sus hasta este punto siempre latentes tensiones con el materialismo naturalista. Había justificado su anterior aceptación del naturalismo aludiendo repetidamente -insisto una vez más en ello- a unos criterios de oportunismo artístico. Había, en fin, que estar al día, seguir la moda de París.

Hay ejemplos de todo esto en el prólogo que escribió para la traducción de Trabajo, así como en otros escritos de esos años últimos de su vida. Mariano Maresca llama "textos exaspera" dos" a algunos de estos escritos y, refiriéndose a los comentarios a Trabajo, dice que en ellos Clarín declara, abiertamente,

su negativa - casi esquizofrénica- a leer determinadas cosas de las que un Zola "socialista" ha escrito en esa novela, y en especial su desdén por la naturaleza moral del trabajo humano. Alas dice expresamente: "Permítaseme soñar un poco...", antes de hablar de "su" Zola, al que quiere salvar de aquel otro al que "se le ha subido la teoría al arte", como decía en un Palique de 1898. La exasperación de esa reseña es, por lo demás, índice de uno de los conflictos más agudos provocados por el fin de siglo en el interior del pensamiento de Alas ${ }^{59}$.

Ese conflicto se debía, por un lado, a que, a pesar de todo, se resistía a romper definitivamente con Zola, a desdecirse por

${ }^{59}$ Mariano Maresca, op. cit., p. 35. 
completo de su vieja admiración por él, y, por otra parte, a que tenía ahora un nuevo modelo ético y estético, Tolstoi. Se había alineado, por tanto, con el "enemigo", pues Zola quiso defender, tanto en "Las tres ciudades" como en "Los cuatro evangelios", la primacía de la ciencia ${ }^{60}$ y de París ${ }^{61}$ sobre la dominante corriente espiritualista, viniera del Vaticano o de Rusia. El conflicto o relación "casi esquizofrénica" de Clarín con Zola era — resulta más que evidente- insalvable.

Clarín, en el prólogo a Trabajo, elogiaba repetidamente a Zola, lo que era -al menos, en parte- una forma de contrarrestar las irreductibles diferencias que lo separaban de su otrora admirado maestro. Clarín había escrito en su prólogo que Zola era "el primer nowbista de su pais... entre los vivus y acaso también del mundo entero" (Trabajo, p. 149), pero, enmendándole subrepticiamente la plana, lo acusaba de haberse ido separando de la doctrina naturalista. Había sido - dice ahora, en 1901 - admirador del "gran genio, la fuerza inmensa de Zola, en la primera mitad de los Rougon", que él había defendido en España "con entusiasmo, sin reserva", pero, en las últimas novelas de la serie "se le ve abrir cada vez más las alas, levantar el vuelo... Algo pierde, pero algo gana" (loc. cit.). El problema, en suma, era que Zola a partir de Germinal inició una etapa de acercamiento al socialismo, etapa que enlazaría posteriormente con el radicalismo de "Las tres ciudades" y de "Los cuatro evangelios". Zola - reconocía Clarín, a la vez que parecía lamentar - "ha vivido mucho cerca del pueblo. Ya su preocupación principal no es artística, es práctica. La llamada cuestión social le preocupa con todo el alma" (Trabajo, p. 150). El naturalismo se había acercado al arte docente, mostrando cada vez más una (para Clarín no aceptable) proclividad a ocuparse de problemas sociológicos. Como dice André Wurmser, comparando Germinal con las novelas de la serie que le habían precedido: "La politique, il l'a mise dans Germinal, comme les écoliers qui ne «mettent l'orthographie» que dans les dictées"62. Clarín, que

${ }^{60}$ Cf. infra, p. 538 .

${ }^{61}$ Zola, en efecto, había querido convertir a París, en su novela homónima, en la capital de la ciencia, la nueva religión de la humanidad.

62 André Wurmser, "Le monde du travail", en Zola, Hachette, Paris, 1969, p. 221. Y refiriéndose a La taberna, decía, citando a Lafargue: "Si al menos hubiera mostrado las causas externas que empujan a su héroe a beber - decía Lafargue-, habría dado a La Taberna un alcance social que la obra no tiene". 
parecía consciente de ello, toma buena nota de que ese proceso se había acentuado definitivamente en Lourdes, Roma y París, en donde Zola era "ya novelista franca y directamente sociológico" (Trabajo, p. 149). Y añade: "Lourdes y Roma no ganan mucho con esto. París recuerda más la garra del león, más sociológico cuando es más artista, no cuando expone más teorías" (loc. cit.). Sin embargo, para un crítico marxista como Jean Fréville, "plus Zola s'élève, moins ses théories physiologiques comptent: elles commandent L'Assommoir, sont nègligeables dans Germinal'"63.

Pero, insisto, el acercamiento de Zola al socialismo y al anarquismo, bastante inocente e inofensivo en Trabajo, como reconoce Clarín ${ }^{64}$, le resultaba a Clarín, a pesar de todo, una denostable desviación de lo que era para él la estética naturalista. La clave de ese adicional motivo de conflicto se encuentra una vez más en el propio Clarín, porque éste ya había tenido en la década de 1890 muy duras polémicas con los anarquistas y los socialistas. Como ha documentado Yvan Lissorgues, en su imprescindible aportación Clarín político, su "desprecio por los anarquistas es absoluto y sin matices" (Lissorgues, p. 231). El 20 de agosto de 1897, en El Heraldo, hacía dialogar así a dos personajes:

- Me parece usted utopista.

- ¿Sabe usted lo que significa u-tópico? El Calvario me parece tópico, un lugar, bastante sólido. Roca viva. Lo utópico, lo absurdo, lo necio, lo repugnante, es hablar de la selección de la humanidad fullera haciendo volar en cachos a la presente; lo utópico es asesinar alevosamente, y tener de mártir la abnegación sin el amor y la virtud; lo utópico es meterse a mejorar el mundo, sin procurar antes la mejora interior, sin refrenarnos a nosotros mismos (ibid., p. 233).

En Vida Nueva, el 19 de septiembre de 1899, atacaba - un motivo por el que Trabajo, ejemplo de literatura docente, lo colocaba como traductor en una posición incómoda ${ }^{65}$ - la propaganda

${ }^{63}$ Apud André Wurmser, art. cit., p. 219.

${ }^{64}$ En el prólogo a Trabajo (ed. cit., p. 148) decía Clarín que ni "su fourierismo redivivo" ni "su anarquismo bonachón" presentaban peligro alguno.

${ }^{65}$ Alude varias veces a ello en su prólogo a Trabajo (ed. cit., pp. 147-154 et passim). 
indigesta de ciertos semisabios y semisabias, apasionados corifeos de un superficial radicalismo, cuyas fuentes filosóficas, cuando las tienen, son el positivismo y el sensualismo ${ }^{66}$ de escalera abajo... Esos cabecillas no siempre obran de mala fe [¿como Zola?], los hay que se engañan a sí mismos, tomando por ciencia sus lecturas fragmentarias de libros de superficial propaganda. Repásese la biblioteca, que a veces la tienen, de estos capataces del radicalismo y se verá que en ella prepondera la ciencia del sectario. Son gente de puro dogmatismo. No saben decir más que por su misal. Son los seminaristas al revés (apud Lissorgues, pp. 236-237).

En Madrid Cómico, el 30 de diciembre de 1899, escribía:

A propósito de ácratas, debo decir, que yo no me burlo de los pobres obreros que estudian lo que pueden. Los ácratas, los capataces, los cabecillas presuntuosos a que yo me refiero una y otra vez, son señoritos o trabajadores honorarios, vamos, holgazanes que se las echan de victimas del capitalismo (Lissorgues, p. 237) ${ }^{67}$.

En cuanto a sus polémicas con los socialistas, en El Heraldo, el 3 de septiembre de 1899, refiriéndose a la necesidad de introducir mejoras en las condiciones de vida de las clases pobres, escribía:

Mi tesis... es: que los pobres, la clase desamparada (valga la verdad), pueden alcanzar sin mengua del individualismo y $\sin$ pedirlas en nombre de la coacción económica muchas mejoras importantísimas. $Y$ si yo llegara a conversar con los obreros en una de esas conferencias públicas, trataría, con mucho gusto, de demostrar que la base filosófica del marxismo se opone a esta desintegración de los fines de la clase obrera, porque unos marxistas directa, otros indirectamente, todos atribuyen al fin económico un carácter primordial, que hace creer al ortodoxo de esa escuela que es ilusoria toda revolución que no tenga por primer móvil el de lo

${ }^{66}$ Cf. infra, p. 541.

${ }^{67}$ Federico Urales, que se sintió aludido en algunos de los comentarios de Clarín, le replicó: "El Sr. Clarín, a pesar de su pluma y de los libros que ha hojeado, que no son pocos, o quizás por ellos, padece gran desarreglo nervioso. En él predomina la intelectualidad, y como todos los que se han apartado de la Naturaleza para acercarse a Dios, hase sentido indispuesto para hacer del misticismo una solución espiritual y material, y del cristianismo, esencialmente místico, un compendio de verdades y virtudes" (apud Lissorgues, p. 244). 
económico, que da forma y carácter a todos los demás fines (ibid., p. 259).

Y también en 1899, con ocasión de la celebración del 1을 de mayo, sentenciaba en La Lucha de Clases:

Es un memorandum (el 1을 de mayo) del acreedor, el obrero, al pagador moroso, el capitalista.

Además, lo que principalmente se pide en el 1 을 de mayo es algo que puede reconocer, todo hombre justo y caritativo, que es un derecho de caridad.

Confesar que los obreros deben tener tiempo para algo más que sudar en favor de todos nosorros, para educarse, para atender a los suyos, no es más que reconocer que los obreros también son hijos de Dios; lo cual no es ninguna paradoja socialista (id., p. 264).

Es sumamente ilustrativo constatar que, durante la crisis clariniana de los años 1895-1901, fuera repitiendo estas mismas ideas, con pequeños matices, a la hora de enjuiciar el naturalismo social y la novela-utopía Trabajo, que era, según Zola, la conclusión lógica de toda su obra ${ }^{68}$. Estas ideas y juicios de Clarín eran también la conclusión de lógica de su quehacer literario e intelectual.

En un artículo sobre Trabajo, aparecido en La Lectura en abril de 1901, escribía Clarín:

En Trabajo hay, a mi ver, un gran poema echado a perder a ratos por un tratado bastante superficial de ciencia (!) sociológica, precipitada y dogmática.

A mí me da pena ver a todo un Zola, que me parece un príncipe del arte, trabajar de aficionado en sociología, en teología, en todo (pero, en fin, con decir sociología basta, porque hoy la antigua erudición a la violeta se llama sociología) (apud RAMOS-GASCón, p. 220).

Viene con un dogma hecho, con una ciencia de segunda mano que no discute, que da por buena, y hace, por ejemplo, de la evolución y de lo que él llama ciencia moderna, su Biblia, su Alcorán, su Talmud. ¿No ha de dar esto pena? (RAmos-Gascón, p. 222).

${ }^{68}$ Ms. de Trabajo, Bibliothèque Nationale de Paris, f. 10334. 
Un gran artista debiera salvarse de la vulgaridad, del positivismo de escalera abajo, que es la peste de los semisabios del día, y de los hombres de voluptuosidad egoísta (que quieren explicar científicamente su egoísmo y sus vicios) a fuerza de genio, de intuiciones poéticas, de aquellos divinos misterios que vislumbraba siempre Shakespeare (ibid., p. 222).

Clarín lamentaba que Zola pensara que estaba actuando en nombre de la ciencia moderna, cuando había científicos que no admitían el materialismo metafísico que éste decía profesar. Según Clarín, si se fijara en ello

podría ver que los menos sospechosos de metafísica tradicional, los más fieles al experimentalismo, son los que menos admiten esas rotundas negaciones del espiritu y de su misterio; como, v. gr., el gran psicólogo norteamericano $\mathbf{W}$. James, que afirmaba hace poco que "no hay un solo argumento realmente científico que autorice para negar la inmortalidad del alma".

Zola, ahora, les niega ese consuelo, esa esperanza, a sus héroes más espirituales, y les manda contentarse con entrar en el torrente de la vida universal; y eso no por mal corazón, que el de Zola es muy bueno, sino... en nombre de la ciencia moderna (id., pp. 233-234).

Clarín consideraba a Morfain el personaje más logrado y más ejemplar de Trabajo, porque su "grandeza espiritual", su "riqueza anímica" era

superior a todas las combinaciones del materialasmo económico, que pueden dar por resultado muy útiles adelantos de la vida del obrero, pero que no suponen los grandes méritos morales que su [sic] abnegación demuestra (id., p. 229).

Pero al mismo tiempo recriminaba a Zola que, teniendo dotes de gran "poeta espiritualista" - la muestra de ello era la muy lograda caracterización de ese personaje-, sacrificara su talento a unas ideas de "teórico positivista y sensualista" y que buscara "el resultado de la dicha hedonista" (id., pp. 229-230). Zola, se lamentaba Clarín,

no dice jamás que su ideal social es el placer, sino la dicha; pero la dicha colectiva que busca es el placer. No es el bien moral, no es el deber de la vida: es. . la satisfacción de nuestras necesidades. $\mathrm{Y}$, en efecto, en la última parte del libro, en los párrafos menos felices, pero más claros, más docentes, Zola nos pinta la felicidad de su 
pueblo... y la hace consistir principalmente en los goces más ordinarios, de puro sensualismo. Mucha paz, mucho amor, pero es para trabajar poco, holgar mucho, trabajar divirtiéndose, tener en casa mucha agua, mucha electricidad, y vestidos de lujo, y piedras preciosas; y para darse besos en los bosques a la luz de la luna... El progreso, visto así, hace al hombre más feliz haciéndole más pequeño de alma, quitándole así la ocasión de la grandeza espiritual (id., p. 230).

Clarín pensaba que los auténticos reformadores sociales, los verdaderos amantes de cambiar la vida pública y encontrar nuevas sendas que abocaran al progreso y al bienestar social, tenían frente a ellos dos alternativas:

O dedicarse directa, inmediatamente a procurar en la sociedad misma que los rodea ese cambio, esa reforma, sin empezar por excaminarse a sí propios y prepararse a su apostolado con la reforma, con el perfeccionamiento de sí mismos; o abstenerse de reformar a los demás, de influir en el medio social, hasta encontrarse dignos de tan magna obra, mediante reforma interior, austera educación del alma, para ponerla en estado de poder servir de veras a la mejora social, merced a obras y acciones que supongan equilibrio moral, lucidez de espíritu, fundadas en la virtud sólida, en el dominio enérgico de las propias pasiones. El primer camino es el que suele seguir la inmensa mayoría de los reformistas, se puede decir que Cristo fue el que enseñó a la humanidad a seguir el segundo, por más que hasta ahora no hayan continuado muchos por tan ardua propedéutica (apud TORRES, p. 244) $)^{69}$.

A continuación, establecía un paralelismo entre la "vida de los grandes santos, que además fueron reformistas sociales", con la de los grandes revolucionarios, concluyendo que si estos últimos, "atendieron mucho más a la perfección de la sociedad que a la propia; pensaron más en los vicios sociales, que en los de su

69 Por otra parte, Clarín recordaba que en Ana Karenina, Levine concluye la novela mostrando una conducta análoga: ". . . mi vida interior ha conquistado su libertad; ya no estará a merced de los acontecimientos, cada minuto de mi existencia tendrá un sentido evidente y profundo, en que podré inspirar mis acciones: el sentido del bien" (apud Torres, p. 245). En Resurrección, Neklindoff descubre, al final de la novela también, que "lo esencial es todavía la reforma interior', el nuevo sentido que le encuentra a la vida; la abnegación, el bien; lo que aprendió en el Sermón de la montaña, el día que lo leyó "a la luz de la aureola espiritual de la gracia" (cf. TorRes, pp. 245246). 
incumbencia", los primeros pusieron más esmero en "el cuidado esencial de la propia conducta, de las virtudes íntimas, base de la sólida caridad" (Torres, p. 244). Y ponía el ejemplo de San Francisco de Asís:

¿Quién reformó más que él? ¿Quién influyó más en el camino íntimo, moral de la sociedad de su tiempo? Pero antes de lanzarse a predicar, y fundar conventos y convertir infieles, empezó por asegurarse de su propia reforma interior, del cambio interior, de la íntima fortaleza, para poder creerse digno instrumento de la obra que quería emprender. Hasta el día de la suprema prueba, cuando venció repugnancias naturales, besando las llagas de leprosos no empezó a creerse digno de procurar la reforma social a que aspiraba (ibid., pp. 244-245).

Clarín, negando validez a las utopías socialistas, de Zola o de otros ideólogos materialistas - pues temía esos modelos, obsesionado por su personal "leyenda de Dios", término que había acuñado en el prólogo a Cuentos morales-, arremetía, una y otra vez, en sus escritos de los años 1895-1901, contra

el prurito noble de hacer bien al prójimo con reformas exteriores, con resortes sociales; pero con la ineficacia que nace de no haber empezado con una seria, profunda, austera reforma moral del mismo reformador (id., p. 245).

Su propuesta, según la recensión de una de sus conferencias dictadas en el Ateneo, en noviembre de 1897:

Yo quisiera referirme a las clases desheredadas, a las clases obreras, aunque en rigor no sean ni desheredadas ni obreras; a los pobres, término más adecuado para su definición, del mismo modo que para mí es preferible a la palabra socialista, la palabra ebionita. Hay que aceptar de la pobreza las muchas cosas que la pobreza tiene buenas.

Hay una manera de entender la cuestión social, que es la predominante, la del socialismo marxiano, estudiada hoy con acierto, aunque ya en decadencia, por los discípulos de Carlos Marx.

Este socialismo es, como se ha dicho, un materialismo de la Historia...

Este materialismo reduce la cuestión social a la cuestión del pan. Primero es vivir que filosofar, se ha dicho; pero la vida no [es] exclusivamente económica. No ha de ser la Religión algo que ven- 
ga a atraer a las masas, complaciendo alegremente sus instintos, sino diciendo siempre las tristes y austeras verdades que deba decir... La Religión no ha de hablar al pobre de panaceas económicas, sino de lo esencial de la vida; porque según dice Brunetière: ¿Cómo queréis que le quitemos al que va a morir el problema de la inmortalidad?

El hombre, antes que un animal, es un ser espiritual. Hemos de llegar a tratar la cuestión sociológica desde este punto de vista ${ }^{70}$.

El Zola de Trabajo le parecía a Clarín obsesionado por unas "fórmulas dogmáticas" con las que se habría propuesto propagar, como tantos otros "seminaristas al revés", unas erróneas negaciones (Trabajo, p. 147). A pesar de la admiración que todavía decia sentir por Zola, el ataque no podia ser, desde su óptica de neoconverso, más descalificador. Lo acusaba, en el prólogo a Trabajo, de ser "materialista, hedonista", y de que hasta fraternizara "con el colectivismo y el anarquismo" (loc. cit.). He aquí lo que separaba al autor de la novela-utopía y a su traductor:

Yo creo en Dios, en el espíritu, en el misterio; y las graves cuestiones sociales no creo que hoy se puedan resolver científicamente; porque el adelanto humano, a tanto, no ha llegado todavía. Las rotundas afirmaciones de Zola sobre Dios, el alma, la evolución, el fin de la vida, la llamada cuestión social, las rechazo, aun más por su contenido, por la mflexibilidad dogmática. Zola, como Agusto Comte, del cual es en Trabajo, en lo esencial, fiel discípulo, es un católico al revés; y así como se ha probado que el organicismo social positivista era una iglesia católica, con su papa a la cabeza, el mismo Comte; la utopía de Trabajo es un catolicismo ateo y hedonista con su pontífice, Lucas (Trabajo, p. 147).

El contramodelo era ahora Tolstoi. Por él había expresado, ya en el prólogo de 1900 a la edición española de Resurrección, un entusiasmo "sin distingos ni reservas" (loc. cit.). Admiraba de Tolstoi, particularmente, su manera de ser religioso, pues siendo

varón de santidad probada, también inventa sociologias; pero siempre hizo lo mismo; ha reflexionado mucho más que Zola, ha vivido mucho más la vida interior, y no se ha dejado llevar por los sectarios ni por los científicos de similor ni por la ciencia de segunda mano admitida dogmáticamente. Por eso, Tolstoi podrá soñar a veces

70 Apud Yvan Lissorgues, La pensée philosphique..., pp. 395-396, en donde se reproduce la recensión de la conferencia de Clarín. 
como sociólogo; pero no es un vulgar sectario del ateísmo, del sensualismo y hasta del anarquismo, en resumidas cuentas, como Zola se nos presenta (RAMOS-GASCÓN, p. 22,5).

Tolstoi era para Clarín un "pedagogo singular" y "cristiano independiente", (Torres, p. 239), quien, a diferencia de otros escritores ni "la lección escueta" ni "la tesis directa nos hace impacientarnos' (ibid., p. 240). Según Clarín, en Resurrección, "a pesar de' que el propósito íntimo del autor es más docente, más interesado que nunca, las digresiones doctrinales se nos dan en dosis menores, en estilo elocuente, y casi siempre agregadas a los pocos renglones, a la lección misma, de modo puramente artistico" (lo cii.). Pero cue Clarín se identificara plenamente con su mensaje, con su propedética, relativiza, cuando menos -hay que convenir-, su argumentación. Como sea, ve en el arte de Tolstoi la plasmación milagrosa de un deseo divino. En el prólogo a Resurreción, afirma:

Lo ha querido Dios; Tolstoi cada vez más olvidado de su genio, humilde de verdad, como buen cristiano, es más poeta, más artista que nunca, sin querer; porque la gracia que Dios ha querido llevar a su corazón, también la derrama sobre su arte, piense en ello o no el artista, pues le ha de servir de instrumento para edificar las almas con el señuelo de la hermosura (RAMosGASCÓN, p. 240),

Clarín, así las cosas, se sintió obligado a justificar las razones por las que se había decidido a traducir una novela de la que necesitaba distanciarse. Dio dos razones. Porque tenía un "espíritu de tolerancia" (Trabajo, p. 147) y porque quiso servir modestamente a la lengua castellana. Decía al final del prólogo a Trabajo:

Me lavo las manos. Feliz yo si evito que todas estas doctrinas anarquistas, materialistas, mezcladas con ideas de amor y justicia, grandes y hermosas, lleguen al pío lector con tantos galicismos como serían de temer, si el libro lo hubiera traducido, por treinta duros, algún hambriento de esos que tienen, en efecto, derecho a no creer en los fueros del lenguaje nacional (p. 154).

Con todo, Clarín era muy consciente de la naturaleza polémica de Trabajo. Era de esperar, por tanto, que sobre el libro caerían, de un lado, las críticas violentas de sus más intransigentes 
enemigos y, de otro, las alabanzas ditirámbicas de sus fervorosos seguidores. Pero su varapalo cayó, principalmente, sobre el bando de "los críticos temporeros, los que hablarán de Trabajo, porque es obra que defiende el socialismo y hasta el anarquismo, y porque es el héroe del affaire, de la ruidosa cuestión de Dreyfus' (RAmos-Gascón, p. 218).

Recuerda que según Cremes: "lo bello por lo bello es un juego infantil, atávico; hoy el arte, si quiere subsistir, necesita servir a una idea, y es bueno o malo según la idea sea buena o mala"' (ibid., p. 219). En consecuencia, dice Clarín: "Con tales dogmas, es claro, estos críticos dirán que admiran Trabajo, que es bellísimo poema, porque son partidarios, como el autor, de abolir la propiedad, de suprimir a Dios y de matar toda esperanza de otra vida" (id., p. 219).

Clarín, que se quiso distanciar de unos y otros, pues "entre los de uno y otro bando, es claro que yo me quedo sin ninguno" (loc. cit.,), con todo tuvo la honestidad de confesar que para él:

si los críticos ladinos y reaccionarios, que se meten a sociólogos, son más antipáticos tal vez; los otros, los reporters y apóstoles, sobre todo, que se meten a críticos, son más intransigentes y mucho más ignorantes. Le tapan a uno la boca. Después de sentar ellos sus dogmas radicales, improvisados por los nervios, no se atreve uno a decir nada, porque todo puede parecerles una injuria personal... Y lo peor es que para [sic] estos seminaristas al revés... es texto santo la fórmula de la pretendida ciencia que buscan en cualquier parte... (RAMOS-GASCÓN, pp. 219-220).

En consecuencia, por tanto, se quedó, después de tanta perífrasis, con los "más antipáticos". Y lo que es más, falló en el pronóstico; porque los críticos "reporters" y "apóstoles" no hicieron una crítica tan de "seminaristas al revés" como había predicho. Así, entre varios ejemplos, cabe señalar que A. C., en La Nueva Era, después de destacar que Zola iba en Trabajo derecho al comunismo y que su solución era perfectamente socialista apuntaba, de manera muy ponderada, que fallaba en el medio, pues "el motor de la transformación social en la obra de Zola no es el Proletariado, sino la generosidad y la sabiduría de algunos magníficos individuos constructores de la sociedad nueva'. Y a continuación, añadía A. C.:

Sí, es verdad que se procede por penetración y que no bastará un decreto del Proletariado vencedor para renovar la sociedad; sí, 
es verdad el número de los que vuelven la espalda a la Burguesía para hacer causa común con el Proletariado; sí, es verdad que la persuasión, la bondad y el desinterés no son factores que retrasen; sí, todo esto ayuda, y mucho; pero se ha de tener presente que la fuerza con la cual logrará el Proletariado emanciparse reside en el Proletariado mismo. Y si este Proletariado cesa de organizarse y de combatir; si cesa de asaltar a la Burguesía, atrincherada en los Poderes político y administrativo, la marcha del progreso cesará, las conquistas alcanzadas se desvanecerán y ninguna individualidad alcanzará a sustituir a la colectividad trabajadora ${ }^{71}$.

Otro ejemplo más. En una reseña aparecida en la Revista Bibliográfica, se celebraba el que Trabajo fuera "un libro profundamente revolucionario", cuya eficacia demoledora y poder disolvente era comparable a "las obras más importantes de los grandes autores libertarios'. Sin embargo, se le recriminaba, también en tono muy mesurado, que tuviera una endeblez doctrinaria, por lo que seguramente "a ningún pensador sólido convencerá la fe fourierista que en su nuevo Evangelio proclama como redentora de la humanidad explotada y envilecida el gran escritor francés', Pero, con todo,

adornado el fourierismo con las galas del estilo zolesco, predicado con la elocuencia, con el entusiasmo, con el optimismo que el nuevo evangelista pone en las páginas que lanza a la muchedumbre esclava del salario, hambrienta de libertad y justicia, no hay quien deje de rendirse al poder de inteligencia tan soberana, y por un momento no se considere ciudadano de aquella Jerusalén feliz, justa, gloriosa, que Lucas Froment erige sobre las ruinas del viejo Beauclair, abominable y maldito ${ }^{72}$.

Curiosamente, fue el propio Clarín quien, en algunos pasajes de sus críticas a la novela, desentonó, actuando como uno de esos "seminaristas al revés" a los que tanta aprensión tenía. Entre otras cosas, se había permitido echarle en cara a Zola que se había decidido a hacer una novela tendenciosa, de contenido social, por razones estrictamente estratégicas, porque se había dado cuenta de que el naturalismo estético estaba " gastado, ago-

${ }^{71}$ A. C., "La última novela de Zola", La Nueva Era, octubre 1901.

${ }^{72}$ Prudencio Rovira, "Trabajo, por Emilio Zola", Nuestro Tiempo, junio 1901. 
tado" (cf. Ramos-Gascón, p. 224). Y luego, con un tono de condescendencia y de superioridad moral, escribió:

Tengo la esperanza de que este verdadero abismo, sin grande$\mathrm{za}$, en que positivamente ha caído Zola, como burgués enamorado del aura popular, no ha de tragarle definitivamente, y creo que a él le ha llevado su escasa preparación para los grandes problemas con que se atreve; no la pequeñez de espíritu (ibid., pp. 226-227).

A un lado lo de la escasa preparación para los grandes problemas, lo de "burgués enamorado del aura popular", era una grave imputación, pues Clarín le estaba acusando veladamente de haber escrito Trabajo movido por una necesidad de popularidad. Clarín, con esta imputación, cerraba filas - empujado por la lógica de su ilogismo- con la crítica ultramontana que no había perdonado a Zola ni su utopía socialista ni el que hubiera participado, unos años antes, en el caso Dreyfus.

El crítico catalán José Yxart ya había llamado la atención sobre los peligros de "abrir camino en el gusto español a las novísimas aspiraciones literarias" (es decir: al espiritualismo), porque en España

los vicios tradicionales de otros idealismos, que nada tienen de nuevos, todavía florecen con lozanía, sin que amenace ahogarlos la vegetación realista, que está muy lejos, entre nosotros, de ser tropical o cosa parecida ${ }^{73}$.

Francisco Caudej Universidad Autónoma de Madrid

${ }^{73}$ Cf. la reseña que hizo Clarín de Realidad, reproducida en L. AlAs, Teoría y crítica de la novela, ed. cit., p. 247. 